\title{
Moderating Effects of Academic Position and Computer Literacy Skills on E-learning Portal Usage: SEM Application on Theory of Planned Behaviour
}

\author{
Mohamed Majeed Mashroofa ${ }^{1}$, Athambawa Haleem ${ }^{2}$ and Aboobucker Jahufer ${ }^{3}$ \\ ${ }^{1}$ Senior Assistant Librarian', Science Library, South Eastern University of Sri Lanka, \\ E-mail: mashroof@seu.ac.lk, \\ ${ }^{2}$ Senior Lecturer in Accounting ${ }^{2}$, Faculty of Management $\mathcal{E}$ Commerce, South Eastern \\ University of Sri Lanka, E-mail: ahaleem@seu.ac.lk \\ ${ }^{3}$ Professor in Statistics ${ }^{3}$, Faculty of Applied Sciences, South Eastern University of Sri Lanka, E- \\ mail: jahufer@seu.ac.lk
}

\begin{abstract}
The main objective of this research is to investigate the moderating effect of academic position and computer literacy level on usage of the online learning portal among academics by examining the factors from the perspective of the Theory of Planned Behaviour as the basis for conceptual model. Academic position and Computer Literacy skills are used as moderators. The population of the study comprised 5399 academics. Systematic proportionate sampling techniques applied to gather data, with 400-sample size. Data were received from only 320 university academics, giving a response rate of $80 \%$. SPSS and AMOS version 23 were instrumented to analyse the data and Structural equation modelling was used to find the model fit and causal relationships. This study reveals that both attitude and subjective norm have influences on the behavioural intention but not the perceived behavioural control. Behavioural intention and perceived behavioural control had a direct association with Portal Usage. Both gender and academic position moderate the association of exogenous and endogenous variables. This study will help to set up new work norms that will set aside time for teaching activities through the E-L portal, prepare policy guidelines, and provide incentives to faculty members to encourage E-L portal usage. Universities can use the finding to improve their concerns of the factors involved, as that would enable the academics to use more effectively the online learning system installed at great cost in the universities. In addition, this theoretically contributes to consider the academic position and the computer literacy skills level as the determinants of portal usage.
\end{abstract}

Keywords:- Academic position, Computer Literacy, E-Learning Portal, MOODLE, VLE, Sri Lanka, Theory of Planned Behaviour

\section{Introduction}

There are different types of portals and they are used for different purposes across the world. At first, it is crucial to understand what a portal is. "A portal is an extensive Internet application which, apart from its ability to display a variety of information, offers various convenient features to the user, such as personalization of page appearance, a web page search engine, file downloading, email, discussion forum, and chat capability", Roszak, et al, (2015). Therefore, an E-L portal is described as a learning platform that supports teaching, learning, course management and provides facilities for

(c) AesthetixMS 2020. This Open Access article is published under a Creative Commons Attribution Non-Commercial 4.0 International License (http://creativecommons.org/licenses/by-nc/4.o/), which permits non-commercial re-use, distribution, and reproduction in any medium, provided the original work is properly cited. For citation use the DOI. For commercial re-use, please contact editor@rupkatha.com. 
interactions. It is a gateway to all learning resources such as Power Point presentations, lecture notes, documents, and videos. An educational portal has a specialized architecture designed for specific purposes, such as meeting the requirements of teaching and learning, especially distance learning, with appropriate functionalities. To develop distance education, suitable facilities must be available to conduct sustainable educational transactions. These transactions need to conduct through the electronic medium and cyberspace after establishing a virtual learning environment or electronic portal. This portal will help the students to access, use structured learning programs, and then get the feedback confidentially from a personalized page or folder.

A very popular software used for managing e-Learning portals is MOODLE. E-L platforms known as 'Course Management System' (CMS), 'Learning Management System' (LMS), and 'Virtual Learning Environment' (VLE). Blackboard, Canvas, Edmodo, DesirezLearn and Google Classroom are other VLEs currently in use. However, there appears to be poor usage of VLEs in the global scenario as indicated by the reviewed literature (Al-Busaidi, 2013; Yatigammana, Johar, and Gunawardhana, 2014; Al-Gahtani, 2016; Chawinga, Zozie, 2017). State universities in Sri Lanka are also using VLEs to some extent. However, despite the Government of Sri Lanka's implementation of several projects and establishment of ICT infrastructures in the state universities, the usage is not up to the expected level (Abeysekera, 2008; Fernando,2011, Ratnapala, 2014; Suraweera, Liew, and Cranefield, 2014). Thus, this is highly important to find the influencing factors on e-Learning portal usage. Main aim of this research is to study attitudinal, normative and control factors that associate with behavioural intention of the academics and in terms of their actual behaviour. Next, it is necessary to assess the moderating effects of computer literacy level and academic position on the exogenous and endogenous variables. The remainder of this section explores the extant literature on e- learning to assess the research gap and to formulate a conceptual framework for this study.

\section{Literature Review}

Bibliographic search was performed by using the databases in Emerald Insight, Science Direct and Taylor \& Francis and the relevant literature downloaded. Out of the retrieved literature, 52\% of the sources had utilized the Technology Acceptance Model (TAM), Davis, (1989) to examine the factors concerning with acceptance of e-Learning portal, adoption and usage behaviour. Moreover, Unified Theory of Acceptance and Use of Technology (UTAUT) and Diffusion of Innovation Theory have been used in $12 \%$ of the studies, while Decomposed Theory of Planned Behaviour (DTPB) (Taylor and Todd, 1995) has been used in $8 \%$ of the studies. Information System Success model, Transactional Distance Theory, Theory of Planned Behaviour (TPB) (Taylor and Todd, 1995), and Hofstede's Dimension of Cultures theory have been utilized rarely at $4 \%$ each. This study chose to use TPB as this theory contains attitudinal, normative and control belief structures. Another reason this study focuses on TPB is because it is a derivative and extended model of TRA (Ajzen, 1991) and TAM, which include important variables that help to find the exact circumstances that affect the e-learning portal usage.

Newcomers imitate and follow the existing practices and beliefs in the organization. This is true in academic institutions, too. At the beginning lecturers follow the practices of their senior faculty members and professors. Therefore, academic position may moderate the E-L usage. Similarly, level of their computer literacy may also moderate the E-L usage. Moderating factors such as academic position, Santos and Okazaki, (2015) and computer literacy level, Eke, (2009) were studied a little in the reviewed literature. 


\subsection{Theory of Reasoned Action (TRA)}

TRA was found in 1975 by Fishbein and Icek Ajzen (1975), which interprets "behavioural intention of any action based on attitude and subjective norms". Attitude means "the belief that results from an evaluation of the positive and negative consequences that could arise by engaging in a particular behaviour." Subjective norms "refer to the perception of pressure to participate in action as a result of the influence of other people." TRA was used widely to investigate intention of users towards a certain innovation, but it was rarely used for E-L studies. However, Wenchieh and Hwang (2010) used TRA with a few more variables to study e-Learning behaviour. Even in 2016, it was used to evaluate e-service adoption by combining it with the Expectation Confirmation Theory (Mou, Shin, Cohen, 2016). Asiri et al., (2012) used TRA and extended TAM to explore the determinant factors of the use of LMS in higher learning institutions of Saudi Arabia. TRA has been broadly used in an array of technology adoption studies by employing its main extensions, which are TAM and TBP.

\subsection{Theory of Planned Behaviour (TPB)}

TPB is also an extension of TRA made by adding the variable, perceived behavioural control, Taylor \& Todd, (1995). This theory considers that behaviour is restricted by the unavailability of some resources and facilities. TPB has an additional component by way of perceived behavioural control $(\mathrm{PBC})$. Furthermore, dependent variable of TPB is actual behavior, so that behavioural intention may act as a mediator.

According to (Ajzen and Fishbein, 1980; Ajzen,1991; Taylor \& Todd 2001] "a person's actual behaviour in performing certain actions is directly influenced by his or her behavioural intention and this in turn is jointly determined by his/ her attitude, subjective norms and perceived behavioural control" while engaging in that behaviour. TPB proposes three influencing factors which determine the intention, Taylor and Todd,(1995b). The very First factor is attitude that defines "the degree to which a person has a favourable or unfavourable evaluation or appraisal of the behaviour in question". Second predictor is subjective norm; this refers to "the perceived social pressure to engage or not to engage in the behavior". The last determinant is the degree of perceived behavioural control (PBC), which refers to "the perceived ease or difficulty of engaging in the behaviour and it is assumed to reflect prior experience as well as anticipated impediments". There is a rule of thumb as, "the more favourable the attitude and subjective norm with respect to a particular behaviour, and the greater the PBC, the stronger should be an individual's intention to engage in that behavior", Ajzen, (1991b). However, in different situations the relative importance of these three variables may vary. All these variables may contribute in different levels. According to TPB, behavioural achievement is predicted directly by using PBC and behavioural intention only. Application of TPB to assess the usage behaviour of academics was discussed in the reviewed literature, which listed several crucial factors. This research study uses this theory with a few additional moderating variables.

\subsection{Computer Literacy and Academic Position}

Digital literacy is also referred as "a person (aged 5-69) is considered as a digital literate person if he/she could use computer, lap top, tablet or smartphone on his/her own", (Computer Literacy Statistics, 2019). According to Adeyinka and Mutala (2008) as cited in (Aboderin, 2019), "computer literacy can be regarded as the possession of basic skills in using the computer". 
According to Adeyinka and Mutala (2008) as cited in Computer Literacy Statistics, (2019), "computer literacy can be viewed as basic skills in using the computer, for example, to save and open a file, use a word processing programme, and send and receive e-mail”. Moderating factors such as academic position and computer literacy level have rarely been studied previously as per the reviewed literature. "Oladunjoye et al., (2014) view computer literacy, an aspect of ICT, as the amount of computer knowledge required and the extent of computer usage", Aboderin (2019). Furthermore, the academic position by Santos and Okazaki (2015) may also moderate the usage. Therefore, level of computer literacy and academic position are considered as moderating variables.

\subsection{Research Model}

"A good model is based on a sound theory" (Sekaran \& Boogie, 2010). Accordingly, the research model was formulated using TPB and the details of these variables have been explained. Based on TPB, this study used attitude, subjective norm and perceived behavioural control as independent variables and actual usage behaviour as the dependent variable. Behavioural intention was used as a mediating variable.

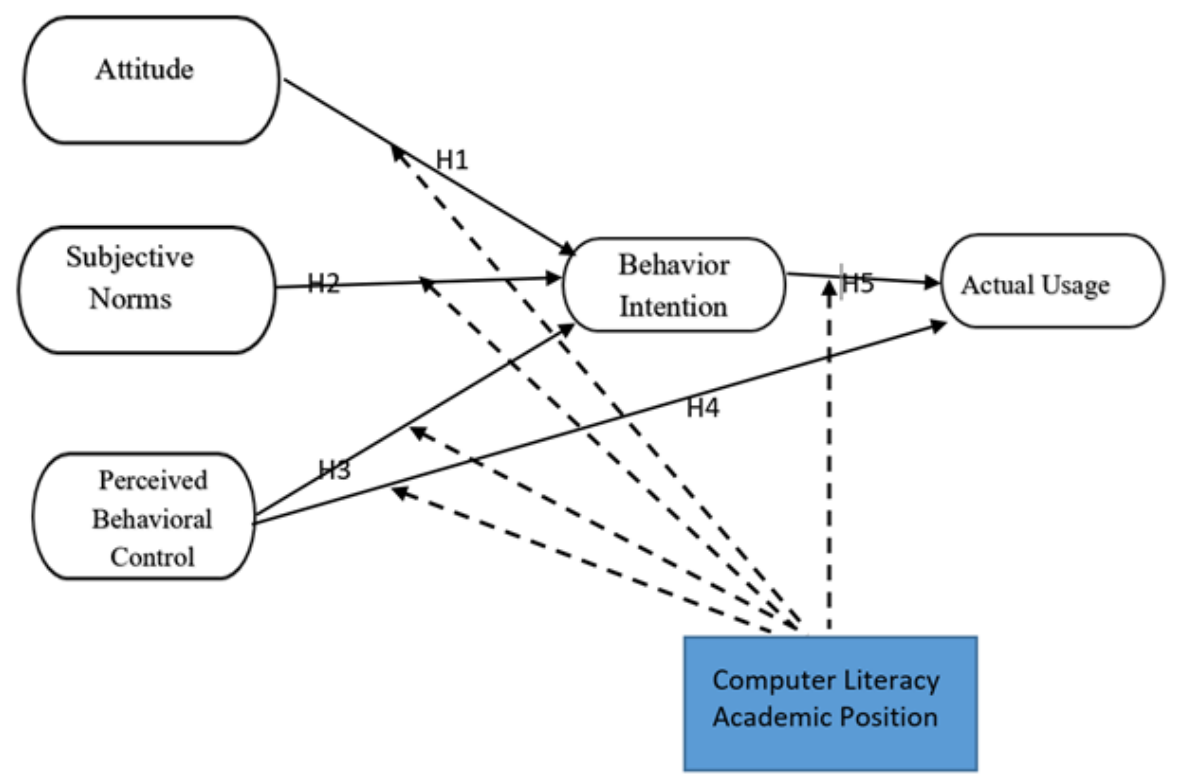

Figure 1: Conceptual Model based on the TPB (Taylor \& Todd, 1995b)

\subsection{Hypotheses Development}

Attitude (ATT) of individuals is widely recorded in the reviewed literature as one of the important variable while examining the use of any innovative technology. ATT is considered as an important variable to influence the intention towards behaviour (Taylor \& Todd, 1995a; 2001). Literature shows that the significance of the attitude as a significant variable and determining factor of intention of system usage directly (Ndubisi,2004; Jaiyeoba \& Iloanya 2019; Ajjan \& Hardshorne,2008). In acceptance and usage of E-L systems too, attitude plays an important role to determine the behavioural intention (Ndubisi, 2004; Tarhini, Hone, Liu \& Tarhini, 2017; Raza, Qazi, Puah, \& ChinHong, 2018). Besides, attitude fails to bring a significant role on behavioural intention in a few studies, (Taylor \& Todd, 2001). Based on this, the first hypothesis was formulated.

$H_{1}$ : Attitude will have an association with behavioural intention 
Literature on innovation adoption in an organizational context suggests that social pressure within a particular organization influences the behaviour and behavioural intention of individuals. "Subjective norms emerge from a need or motivation to satisfy the expectations of important people about a particular behaviour" (Taylor \& Todd, 1995b). This relationship was found to be insignificant in a few studies (Bhattacherjee, 2008). However, previous studies on E-L found that subjective norm has a influence on intention to use (Santos \& Okazaki, 2015; Bhattacherjee, 2008; Lee, 2009). Lecturers who participate in face-to-face or virtual courses may be influenced by the behavioural guidelines of their department or faculty. This might influence their intention; Therefore, the following hypothesis was formed.

H2: Subjective Norms will have association with Behavioural Intention

The association between $\mathrm{PBC}$ and behavioural intention has been widely documented in literature covering both the TPB and DTPB (Fishbein \& Ajzen, 1975, Taylor \& Todd, 1995a). While PBC directly influences usage, it also influences it through BI. Empirical evidences were identified for significant association with behavioural intention in a few E-L studies (Ajjan \& Hardshorne, 2008; Lai 2017, Khasawneh, 2015). On the other hand, a few other research have proven that PBC has an insignificant effect on behavioural intention (Santos \& Okazaki, 2015; Shih \& Fang, 2004). Anyway, the researcher has identified a significant effect from the reviewed literature, and so hypothesis $\mathrm{H}_{3}$ is proposed:

$H_{3}$ : PBC will have association with Behavioural Intention

The literature recommends, "The user's confidence in his capacity is an important component of behavioural control that can determine the behaviour of the user (Fishbein \& Ajzen, 1975). PBC had been proven to have a significant relationship with actual behaviour (Taylor \& Todd, 1995a; Santos \& Okazaki, 2015; Lai, 2017; Kriek \& Stols, 2010). Therefore, it is crucial to study the influence of PBC on the dependent variable and so the below hypothesis was suggested.

$H_{4}$ : There is an association between PBC and Actual Behaviour

Finally, the association between behavioural intention to use and actual intention was found extensively in the reviewed research studies (Davis, 1989; Taylor \& Todd,1995b; Ajzen \& Fishbein, 1981;1980). "Several studies have considered its use as a complete measurement of all its factors in their various extensions" (Taylor \& Todd, 1995b). They also considered the behavioural intention as reasonably a perfect predictor of future behaviour, qualifying the intention to use it as adequate estimation to measure the acceptance of online teaching, though occasionally (Saadé, Tan, \& Kira, 2008) a weak relationship was found. Hence, the fifth hypothesis was suggested.

$H_{5}$ : "Behavioural Intention has a significant relationship with User Behaviour".

In this study, Academic position was categorised into three groups, namely Professors, Senior Lecturers and Lecturers and the moderating effects of Academic position on the determinants of actual behaviour were tested. Similarly, Computer Literacy level also was categorized in to three as beginning level, moderating level and expert level. Hence, the following hypotheses were suggested to evaluate the moderation effect.

H6: Computer Literacy level moderates the association between BI and Actual Behaviour H7: Academic Position moderates the association between BI and Usage Behaviour 


\section{Research Methodology}

\subsection{Sampling}

This study was conducted using a self-administered structured questionnaire to collect data. Population of the study was 5399, representing the number of permanent academic staff in the state universities of Sri Lanka that come under the UGC. Though sample size was 357 as per the table of Krejcie and Morgan (1970), as cited by Sekeran and Boogie, (2010), these researchers administered 400 questionnaires with the aim of receiving the required response rate.

Since academic position is considered as a moderator it is crucial to consist all type of academic categories within sample. Therefore, stratified sampling method was applied for designing sample. Out of 400 questionnaires distributed, 320 were returned. The response rate was 8o\%. After screening the data and excluding questionnaires with unsuitable, miscoded and missing information and those with outliers, only the data received from 312 respondents were utilized for analysing. Quantitative and explorative method was used to retrieve the results. Statistical software SPSS and Amos version 23 were employed to analyse data. Then, the reliability and validity were confirmed before assessing the model fit. Through SEM, path analysis was estimated to measure and elucidate the hypothesised relationships of the model.

\subsection{Measures}

The items measuring attitude, subjective norms, perceived behavioural control, behavioural intention and actual behaviour were adapted from the extant literature, especially from the previous research of (Taylor \& Todd, 1995b; Santos \& Okazaki, 2015; Ajjan \& Hartshorne, 2008) to suit the research model. The questionnaire was developed with a 7-point Likert scale to measure the constructs. Questions were scaled from 1 (strongly disagree) to 7 (strongly agree). Three professors, one from Malaysia and two from private and state universities in Sri Lanka carefully went through the questionnaire. According to their suggestions, questionnaire was further edited and tweaked and the first version was made ready for a pilot study. A sample of 35 members were administered the questionnaire for a pilot test. The reliability of the variables was confirmed by assessing the Cronbach alpha value. All constructs attained a Cronbach alpha value greater than 0.7 (Hair, Black, Babin \& Anderson; Nunnally, 1978; Chinna \& Yuen, 2015) with the inter item correlation falling between $0.3-0.85$. Then the questionnaire was confirmed for reliability and the face validity was confirmed with the opinion of two professors before administering it to the study sample. Measures for the moderating variables of 'gender' and 'academic position' were given two (male/ female) and three options (lecturer, senior lecturer and professor), respectively.

\section{Analysis \\ 4.1 Demographic Characteristics of Respondents}

Among the respondents, 31.3\% were from the Science and Technology field, $41.4 \%$ were lecturers, $52.6 \%$ were males and $47.4 \%$ were females. This survey covered all 15 state owned higher learning institutions that comes under the purview of University Grants Commission (UGC) in Sri Lanka. Considering the academic categories; $41.4 \%$ were senior lecturers and professors were only $11.6 \%$. Direct questions on the usage of E-L revealed that less than half of the respondents (only 44.4\%) were using e-Learning portals at present. 


\subsection{Type of E-Learning Portals}

Most (96.7\%) of the university academics have selected MOODLE as their universities' e-Learning portal under the name of CMS, LMS and VLE, while 3.3\% have selected Blackboard. "Moodle, like any educational technology has the required capabilities to be used for activities that augment or go beyond face-to-face instructional delivery", (Edumadze, 2019).

\subsection{Descriptive Analysis}

Confirmatory factor analysis using structural equation modelling (SEM) was considered appropriate, as it is very effective at analysing the causal relationships between constructs (Hair et al., 2010). Reliability and validity test were ensured for the Scale items of the constructs. If the inter-item correlation between items is within $0.3^{-0.9}$, all items will correlate adequately in all five constructs, (Chinna \& Yuen, 2015). The Cronbach $\alpha$ and the CR value should be more than 0.7 as per (Hair et al., 2010). The Cronbach $\alpha$ for attitude, subjective norm, perceived behavioural control, behavioural intention and actual behaviour have values of $0.872,0.848,0.860,0.900$ and 0.817 , respectively. Hence, as the Cronbach alpha values meets the criteria for the said constructs can be considered as acceptable level of for the scale reliability, (Nunnally, 1978).

The Kaiser-Meyer-Olkin (KMO) test was done to determine the sample adequacy and the acceptable level was greater than 0.5 (Hair et al., 2010). The Kaiser-Meyer-Olkin for attitude, subjective norm, perceived behavioural control, behavioural intention and actual behaviour were $0.831,0.807,0.817$, 0.837 and 0.796 , respectively. The range of factor metrics for ATT, subjective norm, behavioural control, behavioural intention and actual behaviour were o.844-0.868, o.803-0.843, o.851-0.905, $0.837-0.911$ and $0.728-0.836$, respectively. Therefore, all items for each of the constructs met with the rule of thumb, with factor loading value above 0.5 , which is considered the minimum needed for factor analysis. The AVE for attitude, subjective norm, perceived behavioural control, behavioural intention and actual behaviour were $0.622,0.602,0.708,0.701$ and 0.535 , respectively.

Table 1: Discriminant validity of the variables in the model

\begin{tabular}{|l|c|l|l|l|l|}
\hline & ATT & SN & PBC & BI & AB \\
\hline ATT & 0.622 & & & & \\
\hline SN & 0.114 & 0.602 & & & \\
\hline PBC & 0.037 & 0.050 & 0.708 & & \\
\hline BI & 0.266 & 0.141 & 0.031 & 0.701 & \\
\hline AB & 0.042 & 0.014 & 0.109 & 0.071 & 0.535 \\
\hline
\end{tabular}

\subsection{Model Testing}

After confirming the reliability, validity, sample adequacy and factor loading by using SPSS software, CFA was carried out using AMOS to test the model fit and causal relationship. Parameters of multiple goodness-of-fit indices were applied to examine the model fitness. Following threshold values were applied for model fit: Chi-square/df<3, RMR<.05, GFI >.9, AGFI>.9, CFI >.9, RMSEA<.o8 as indicated (Hair et al., 2010).

Table 2: Model fit parameters of all 5 constructs 


\begin{tabular}{lllllll}
\hline Constructs & CMIN/DF & RMR & GFI & TLI & CFI & RMSEA \\
\hline Attitude & 1.548 & 0.007 & 0.995 & 0.994 & 0.998 & 0.043 \\
\hline Subjective Norm & 2.011 & 0.021 & 0.997 & 0.988 & 0.978 & 0.058 \\
\hline $\begin{array}{l}\text { Perceived Behavioural } \\
\text { Control }\end{array}$ & 1.259 & 0.006 & 0.998 & 0.998 & 0.978 & 0.029 \\
\hline Behavioural Intention & 1.723 & 0.009 & 0.995 & 0.994 & 0.998 & 0.049 \\
\hline Actual Behaviour & 1.554 & 0.023 & 0.995 & 0.992 & 0.997 & 0.043 \\
\hline
\end{tabular}

Measurement models for each individual constructs exhibited sufficient values of indices within the threshold.

\subsection{Results of Measurement Model}

Overall model (attitude, subjective norm, perceived behavioural control, behavioural intention and actual behaviour) was accepted once error terms were corrected. In this model that were four pairs. Then the goodness of fit indices were Chi square/df (1.465<3); TLI (0.974>0.9), CFI (0.978>0.9), and RMSEA (0.039< 0.08) within the threshold. Then the discriminant validity was tested, (refer table 1 ). AVE values of all constructs were greater than the corresponding R-square values. Therefore, sufficient discriminant validity between the construct was attained.

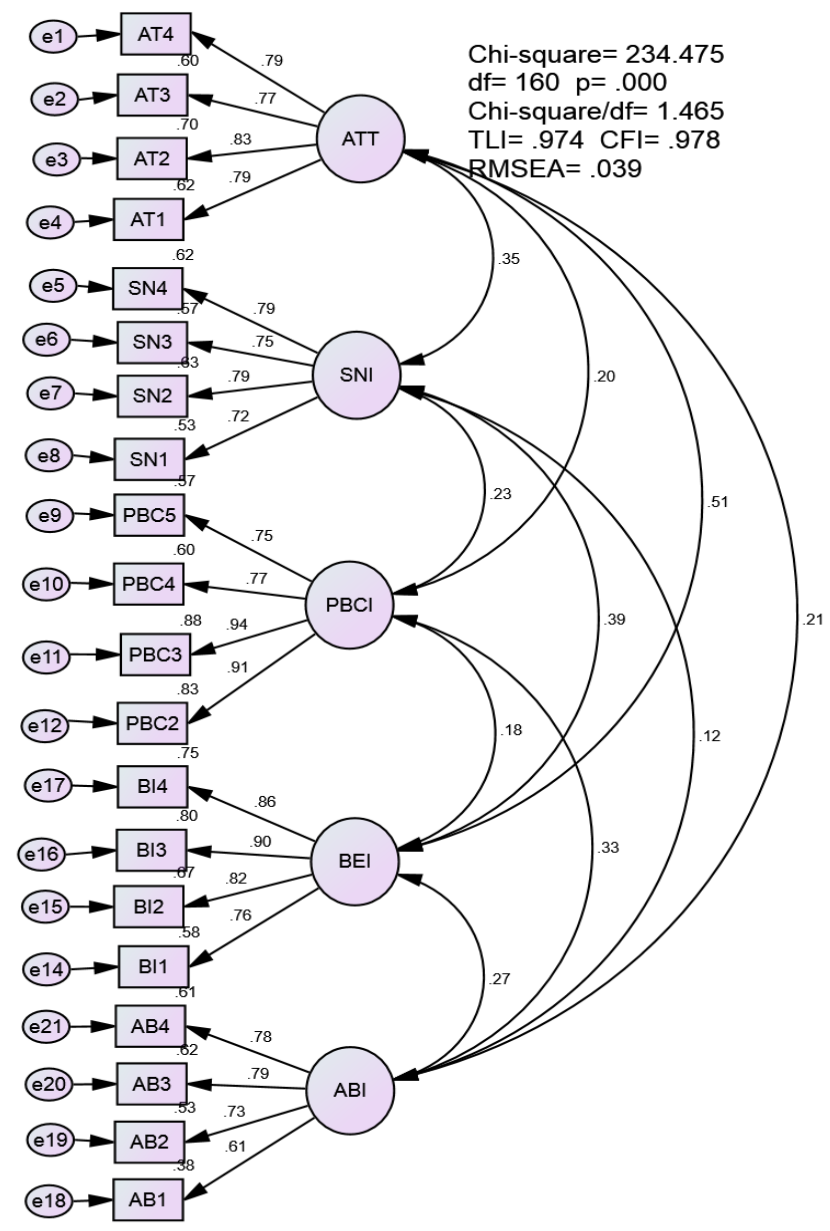

Figure 2: Overall Measurement model 


\subsubsection{Results of Structural Model}

In SEM, developing the structural model is the next stage for testing the hypotheses. The overall measurement model was then transferred as the structural model. Then model fit indices were assessed. Results show that the threshold levels for goodness of fit indices were attained; Chi square/df was $1.708<3$, TLI, and CFI were 0.960 , and 0.965 respectively, and the RMSEA was $0.048<$ than 0.08 as specified, (Hair et al., 2010). This outcome exposes that the model fit is good enough and so it is accepted as a valued model. According to (Hair et al., 2010), "if any three or four of the goodness of fit indices are within the threshold then the entire model is acceptable for further analysis and therefore, testing of the hypotheses can be continued".

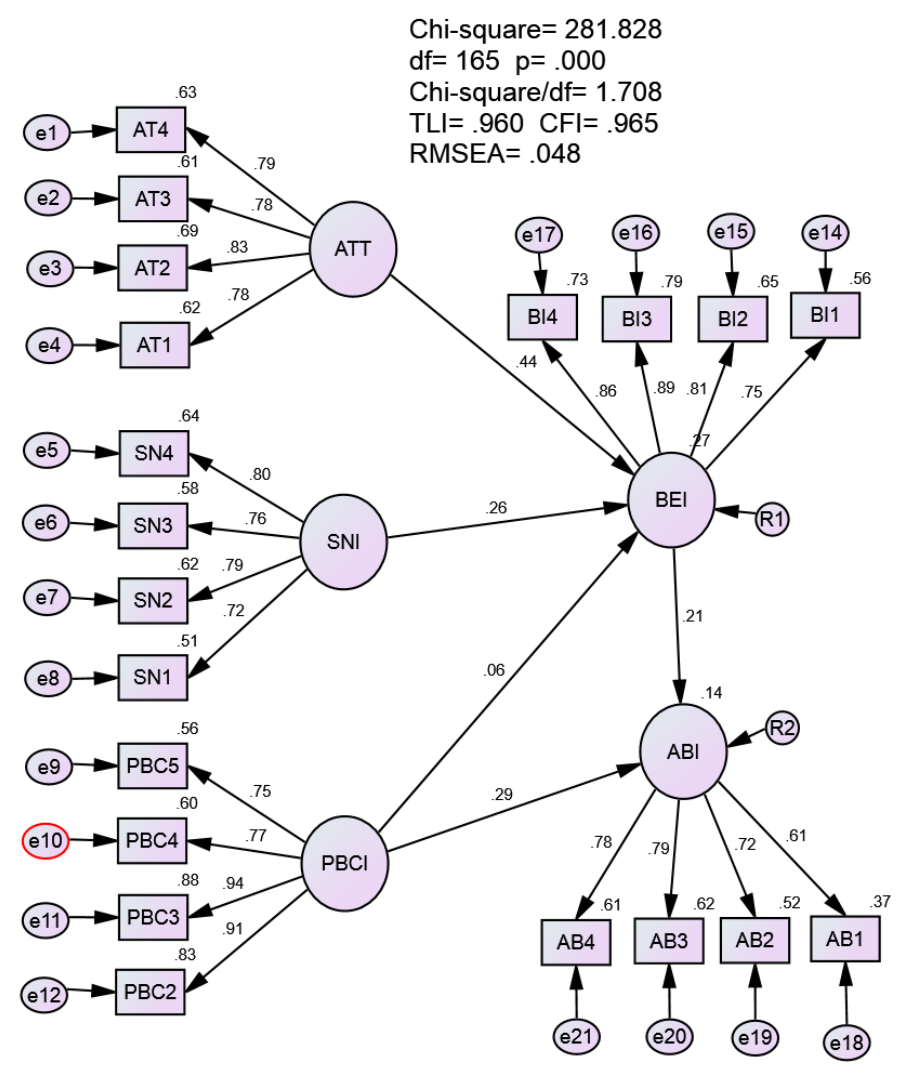

Figure 3: Overall structural model

\subsubsection{Hypotheses Testing}

Scholars used certain values such as CR value, $\mathrm{p}$ value and beta value to test the hypotheses. Values of CR and standard regression estimate (beta) must be more than 1.96 at 0.05 significance level and greater than 0.2 respectively, (Robert Ho, 2006). Results of path analysis were used to draw the conclusion based on the threshold given Robert Ho, (2006). 
Table 3: Regression values of conceptual model

\begin{tabular}{|l|c|c|c|c|c|c|l|}
\hline Path & Hypotheses & $\begin{array}{c}\text { Unst. } \\
\text { Reg. } \\
\text { weight }\end{array}$ & S.E. & $\begin{array}{c}\text { Standar } \\
\text { d Reg. } \\
\text { weight }\end{array}$ & C.R. & $\begin{array}{c}\text { Sig. } \\
\text { level }\end{array}$ & Conclusion \\
\hline ATT <--- BI & $\mathrm{H}_{1}$ & 0.603 & 0.088 & 0.442 & 6.818 & 0.000 & supported \\
\hline SN <--- BI & $\mathrm{H}_{2}$ & 0.206 & 0.049 & 0.258 & 4.205 & 0.000 & Supported \\
\hline PBC <--- BI & $\mathrm{H}_{3}$ & 0.045 & 0.042 & 0.060 & 1.074 & 0.283 & Not Supported \\
\hline PBC <--- AB & $\mathrm{H}_{4}$ & 0.266 & 0.058 & 0.292 & 4.549 & 0.000 & Supported \\
\hline AB <--- BI & $\mathrm{H}_{5}$ & 0.256 & 0.078 & 0.211 & 3.262 & 0.001 & Supported \\
\hline
\end{tabular}

$\mathrm{H}_{1}$ tests the relationship between attitude (ATT) and behavioural intention (BI). As shown in above Table 2, a relationship between ATT and BI exists as the standardized regression coefficient of the path relationship is statistically significant $(r=0.442, p=0.000$ and $C R 6.818>1.96)$. Therefore, data supports for $\mathrm{H}_{1}$.

$\mathrm{H}_{2}$ tests the relationship between subjective norm (SN) and behavioural intention (BI). Table 3 depicts a positive relationship between $\mathrm{SN}$ and $\mathrm{BI}$ as the standardized regression coefficient is statistically significant $(\mathrm{r}=0.258, \mathrm{p}=0.000$ and $C R \quad 4.205>1.96)$. Therefore, Therefore, data supports for $\mathrm{H}_{2}$.

$\mathrm{H}_{3}$ tests the relationship between perceived behavioural control (PBC) and behavioural intention (BI). There is no association between $\mathrm{PBC}$ and $\mathrm{BI}$ as per the standardized regression coefficient of the path relationship is statistically significant $(\mathrm{r}=0.060, \mathrm{p}=0.283<0.05, \mathrm{CR}=1.074<1.96)$. Therefore, data is not supported for $\mathrm{H}_{3}$.

$\mathrm{H}_{4}$ tests the relationship between perceived behavioural control (PBC) and actual behaviour (AB). There is a positive association of $\mathrm{PBC}$ on $\mathrm{AB}$, as the standardized regression coefficient of the path relationship is statistically significant $(\mathrm{r}=0.292, \mathrm{p}=0.000, \mathrm{CR}=4.549>1.96)$. Therefore, data supports for $\mathrm{H}_{4}$.

$\mathrm{H}_{5}$ examines the relationship between the behavioural intention (BI) and the actual behaviour (AB). There is a positive relationship is shown in Table 3, between actual behaviour and behavioural intention as the standardized regression coefficient of the path relationship is statistically significant ( $\mathrm{r}=0.211, \mathrm{p}=0.001<0.05, \mathrm{CR}=3.262>1.96$ ). Therefore, data supports for $\mathrm{H}_{5}$.

\subsubsection{Moderation Effects}

Moderating variable may alter the causal relationship between exogenous and endogenous variables. To examine the moderating effect, multi-group analysis was done through which data are grouped according to the moderator already defined. Though six models were created during the tests and labelled as 'unconstrained', 'measurement weights', 'structural weights', 'structural covariance', 'structural residuals' and 'measurement residuals', researcher was interested only in unconstrained and measurement residuals. As a rule of thumb, if the unconstrained model is better than the measurement residual model, it can be concluded that moderating effect presents (Hair et al., 2010). A multi-group CFA was performed to compare the two groups to find out if the variant model (unconstrained) differs from the invariant (measurement residual) model. While testing the 
moderating effect of computer literacy level, the measurement residuals $\mathrm{X}_{2}$ was greater than unconstrained $\mathrm{X}_{2}$ based on $\Delta \mathrm{X}_{2}(\mathrm{CIMIN})=89.986$ (534.185-444.199); $\Delta \mathrm{df}=49$ (371-322); $\mathrm{p}=0.000$. Hence, the unconstrained model was found to be better than the measurement residuals model based on the indices. Therefore, the computer literacy level has a moderating effect on the determinants of actual usage behaviour in the overall model. The measurement residual model showed a significant $\mathrm{p}$-value $=0.000<0.05$. Hence, there was a significant moderating effect of gender on the overall model.

Table 4: Regression Weight Estimates for Unconstrained Model for Computer Literacy Level

\begin{tabular}{|l|l|c|c|c|c|c|l|}
\hline & & Estimate & SE & CR & P & $\begin{array}{c}\text { Standardized } \\
\text { Reg. weight }\end{array}$ & Conclusion \\
\hline BI <--- & ATT & & & & & & \\
\hline & Expert & 0.483 & 0.109 & 4.431 & 0.000 & 0.358 & Significant \\
\hline & Intermediate & 0.931 & 0.182 & 5.103 & 0.000 & 0.585 & Significant \\
\hline BI <--- & SN & & & & & & \\
\hline & Expert & 0.271 & 0.063 & 4.315 & 0.000 & 0.354 & Significant \\
\hline & Intermediate & 0.084 & 0.081 & 1.045 & 0.296 & 0,091 & Insignificant \\
\hline BI $<---$ & PBC & & & & & & \\
\hline & Expert & 0.086 & 0.056 & 1.546 & 0.122 & 0.112 & Insignificant \\
\hline & Intermediate & 0.003 & 0.061 & 0.054 & 0.957 & 0.004 & Insignificant \\
\hline BI $<---$ & AB & & & & & & \\
\hline & Expert & 0.165 & 0.104 & 1.590 & 0.112 & 0.128 & Insignificant \\
\hline & Intermediate & 0.355 & 0.113 & 3.136 & 0.002 & 0.333 & Significant \\
\hline PBC <--- & AB & & & & & & \\
\hline & Expert & 0.420 & 0.084 & 5.001 & 0.000 & 0.420 & Significant \\
\hline & Intermediate & 0.148 & 0.077 & 1.933 & 0.053 & 0.187 & Significant \\
\hline
\end{tabular}

"If beta for group one is significant and beta for group two is insignificant there will be a moderating effect", (Hair et al., 2010). Hence, when beta value was examined against the p values it was found that computer literacy level moderates the association between subjective norm and behavioural intention, as well as behavioural intention and actual usage behaviour. Therefore, hypothesis $\mathrm{H}_{9}$ is accepted.

H6: Computer Literacy moderates the association between exogenous and endogenous variables

Similarly, moderating effect of academic status was also tested. The measurement residual $\mathrm{X}_{2}$ is greater than unconstrained $\mathrm{X}_{2}$ based on $\Delta \mathrm{X}_{2}(\mathrm{CIMIN})=153.899(837.950-684.051) ; \Delta \mathrm{df}=98\left(5^{8} 1^{-}\right.$ 483); $\mathrm{p}=0.000$. The unconstrained model was found to be better than the measurement residuals model because of the indices. Therefore, academic position has a moderating effect on the determinants of actual behaviour in the overall model.

Table 5: Regression Weight Estimates for Unconstrained Model for Academic Position

\begin{tabular}{|l|l|c|c|c|c|c|l|}
\hline & & Estimate & SE & CR & P & $\begin{array}{c}\text { Standardized } \\
\text { Reg.weight }\end{array}$ & Conclusion \\
\hline BI & ATT & & & & & & \\
\hline & Professor & 1.1016 & 0.315 & 3.220 & 0.001 & 0.465 & Significant \\
\hline & $\begin{array}{l}\text { Senior } \\
\text { Lecturers }\end{array}$ & 0.445 & 0.125 & 3.566 & 0.000 & 0.415 & Significant \\
\hline
\end{tabular}




\begin{tabular}{|l|l|c|c|c|c|c|l|}
\hline & Lecturers & 0.587 & 0.127 & 4.617 & 0.000 & 0.433 & Significant \\
\hline BI & SN & & & & & & \\
\hline & Professor & 0.271 & 0.063 & 4.315 & 0.000 & 0.267 & Significant \\
\hline & $\begin{array}{l}\text { Senior } \\
\text { Lecturers }\end{array}$ & 0.395 & 0.149 & 2.653 & 0.008 & 0.147 & Significant \\
\hline & Lecturers & 0.170 & 0.057 & 2.977 & 0.003 & 0.253 & Significant \\
\hline BI & PBC & & & & & & \\
\hline & Professor & 0.178 & 0.102 & 1.738 & 0.082 & 0.195 & Insignificant \\
\hline & $\begin{array}{l}\text { Senior } \\
\text { Lecturers }\end{array}$ & 0.095 & 0.065 & 1.451 & 0.147 & 0.350 & Insignificant \\
\hline BI & Lecturers & -0.053 & 0.058 & -0.914 & 0.361 & -0.072 & Insignificant \\
\hline & AB & & & & & & \\
\hline & Professor & 0.144 & 0.155 & 0.929 & 0.353 & 0.121 & Insignificant \\
\hline & $\begin{array}{l}\text { Senior } \\
\text { Lecturers }\end{array}$ & 0.338 & 0.135 & 2.498 & 0.013 & 0.136 & Significant \\
\hline & Lecturers & 0.309 & 0.120 & 2.577 & 0.010 & 0.234 & Significant \\
\hline PBC & AB & & & & & & Insignificant \\
\hline & Professor & 0.365 & 0.144 & 2.533 & 0.11 & 0.338 & Insignificant \\
\hline & $\begin{array}{l}\text { Senior } \\
\text { Lecturers }\end{array}$ & 0.079 & 0.076 & 1.044 & 0.297 & 0.373 & Significant \\
\hline & Lecturers & 0.353 & 0.087 & 4.047 & 0.000 & 0.366 & \\
\hline
\end{tabular}

Considering the individual path and the behavioural intention, the actual usage behaviour is moderated by academic position. Similarly, academic position moderates the effect of perceived behavioural control and the actual usage behaviour. Therefore, hypothesis $\mathrm{H}_{7}$ is accepted.

H1o: Academic position moderates the association between exogenous and endogenous variables

\section{Discussion}

This research is based on a few research questions, the foremost of which is, "what are the factors that influence the behavioural intention and actual usage of e-learning portals"? Next question is whether academic position and computer literacy level of the academics moderate the actual usage of e-learning portals. When considering the $\mathrm{CR}$ value of all associated factors it is seen that they all have a positive association at less than $0.05 \mathrm{p}$ value, except perceived behavioural control (PBC) to behavioural intention (BI). This result is in line with that of Santos and Okazaki (2015). Only attitude and subjective norm influence the behavioural intention, whilst the perceived behavioural control is not associated with behavioural intention. Perceived behavioural control also has a direct and positive association with actual behaviour. While examining the association between $\mathrm{BI}$ and $\mathrm{AB}$ it is identified that this also has a positive and significant association.

Literature shows widely that the attitude towards the application of certain technologies would be a key determinant of the final behaviour (Taylor \& Todd, 1995b; Taylor \& Todd, 2001). According to the confirmatory factor analysis of this study, attitude is closely related to the behavioural intention; attitude also has an indirect relationship with actual usage. This is in par with the findings of a few other studies (Taylor \& Todd, 1995; Ajzen \& Fishbein, 1980; Shih \& Fang, 2004; Ajjan \& Hardshorne, 2008). 
Results of this study showed that SN is also significantly associated with BI. This is in line with previous studies on online teaching (Taylor \& Todd, 1995b; Shih \& Fang 2004; Ajjan \& Hardshorne, 2008; Bhattacherjee, 2008; Lee, 2009).

On the other hand, PBC has no statistically significant relationship with behavioural intention. This is in line with some studies (Shih \& Fang, 2004; Santos \& Okazaki, 2015) but contradicts some other studies (Taylor \& Todd, 1995b; Ajjan \& Hardshorne, 2008).

Similarly, behavioural intention also has a statistically significant association with actual behaviour. This result is consistent with a few studies, (Taylor \& Todd, 1995b, Ajzen \& Fishbein,198o; Shih \& Fang, 2004; Ajjan \& Hardshorne, 2008). Moreover, it is imperative to indicate that both academic position and computer literacy moderate the relationship between independent and dependent variables. Though the academics have the attitudinal normative and control factors positively, their intention as well as portal usage are controlled by these two factors. Professors are highest in the position, their usage is limited as they might engage with other activities like curricula revisions, quality assurance and staff development, etc.

\section{Contribution of this Study}

The final structural model can be considered as a model appropriate to the constructs of e-learning usage behaviour (Refer Figure 3). According to the reviewed literature, $52 \%$ of the studies adopted the TAM and its extensions for E-L adoption and only $8 \%$ of the studies adopted TPB for e-Learning studies. Theories such as TPB and the empirical studies have paid little attention to the factors influencing e-Learning usage. Hence, this particular research has made a significant input by determining the factors influencing E-L portal usage and the moderating effect of academic position and computer literacy level. Therefore, this study can also be considered as one among very few in which TPB has been used in this area of knowledge. This is an entirely original research of which the findings implied not only in the Sri Lankan context but also in the perspective of developing nations.

Another interesting aspect that the model postulated was social influence in terms of subjective norm, which TAM does not posit. It was confirmed that peer groups, superiors or any other social factors have a positive association on behavioural intention, which in turn reflects the E-L portal usage.

This introduces several empirical inputs, such as the moderating effect of computer literacy level as well as the academic position together with attitudinal, normative and control factors. Even though the e-Learning system is sufficiently well known and widespread in the university environment, perhaps the academic position accelerates the usage. One possible interpretation of this result is that this might be due to heavy workload of academics in higher positions because their involvement with university ventures might have reduced the usage at professor level compared to senior lecturers and lecturers. Moderating effects of level of computer literacy and academic position is a new attempt at research in this area. The existing literature rarely mentions the effects of these variables. This model can theoretically contribute to future researchers who could apply the same methods in related studies.

A new cohort of population was tested in the local context. Hence, this study is a pioneering study on e-Learning portal usage by all the academics in Sri Lankan public universities which are controlled by the UGC. This research applied a proportionate, stratified sampling technique to select the study sample, so the results could be generalized to cover all Sri Lankan state universities. 
This study will help to set up new work norms that will set aside time for teaching activities through the E-L portal, prepare policy guidelines, and provide incentives to faculty members to encourage EL portal usage. Universities can use the outcomes of this research to develop their understanding of the factors involved, as that would enable the academics to use more effectively the MOODLE/ VLE system installed at great cost in the universities.

\section{Limitations and Future Directions}

The generalized results of this research are applicable mainly to state funded universities and may not be applicable to the private universities that are beginning to emerge in Sri Lanka. It is recommended that in future a comparative study should be conducted in this area including both public and private universities. In addition, this research did not address any factor related to the teaching and learning pedagogy and this must also be given attention in future studies. Though cultural factors were highlighted by a few researchers (Suraweera, Liew \& Cranefield, 2014; Thowfeek \& Jaafar, 2012), this study does not address those factors. In addition, the functionalities of the E-L system, its user friendliness, etc. must be investigated in future studies.

\section{Conclusion}

The result shows that online learning usage is influenced mainly by behavioural intention and perceived behavioural control, both directly by attitude and subjective norm, and indirectly, too. Behavioural intention could be enhanced by the positive attitude as well as the subjective norm, which finally would prime to the actual behaviour. Findings of this study show that attitude, subjective norm and behavioural control together have determined the AB.

The findings also suggest that a significant positive relationship is found between attitude and behavioural intention, and subjective norm and behavioural intention, but not with behavioural control and behavioural intention. Similarly, there is a significant positive association between behavioural intention and actual behaviour. Behavioural control and actual behaviour also has significant positive association. Therefore, this study concluded that behavioural intention is determined by individual's attitude and normative belief but not really by the control factors. Instead, actual behaviour has a positive association with control factors. Computer Literacy Level and academic position act as moderators. Therefore, it is imperative to indicate that these two moderating variables have a profound effect on exogenous variables, behavioural intention and actual behaviour.

\section{References}

Abeysekera, N.(2008), "The Study of How the Introduction of Online Learning to Traditional Distance Learning System Impact on Students--Special Reference to Open University of Sri Lanka”, Proceedings of The Canadian Network for Innovation in Education (CNIE) conference: Canada.

Aboderin, O. S. (2019), "A Mulitidisciplinary study on the relationship between ICT literacy level and academic performance of e learners in an e learning setting", Journal of Management administration, pp1-23. Retrieved from file://D:/jomad_n1_2019_a6.pdf

Ajjan, H., and Hardshorne, R.(2008), "Investigating faculty decisions to about web 2.0 technologies: theory and empirical test”, Internet and Higher Education, 11, pp71-80. 
Ajzen, I.(1991), "The Theory of planned behavior". Organizational Behavior and Human Decision Processes, 50(2), pp179-211, 1991.

Ajzen, I., and Fishbein, M. (1980), Understanding attitudes and predicting social behavior, Englewood Cliffs: NJ: Prentice-Hall.

Al-Busaidi, K. A.(2013), “An empirical investigation linking learners' adoption of blended learning to their intention of full e-learning. Learning”. Behaviour E Information Technology, 32(11), pp1168-1176. Retrieved from http:// dx.doi.org / 10.108o /0144929X.

Al-Gahtani, S.(2016), "Empirical investigation of e - learning acceptance and assimilation : A structural equation model”, Applied Computing and Informatics., 12, pp. 27-50. Retrieved from http://www.sciencedirect.com.

Asiri, S., Mahmud, M.J. , Abu Bakar, R., K. \& Ayub, M., Fauzi, A.(2012). Factors Influencing the Use of Learning Management System in Saudi Arabian Higher Education: A Theoretical Framework. Higher Education Studies, 2(2), 125-137. doi:10.5539/hes.v2n2p125

Bhattacherjee, A. (2008), "Acceptance of Internet applications services: the case of electronic brokerages”, IEEE Transactions on Systems, Man, and Cybernetics-Part A: Systems and Humans, 30, pp 411-420.

Chawinga, W., Zozie, P.A. (2016), "Increasing Access to Higher Education Through Open and Distance Learning: Empirical Findings From Mzuzu University, Malawi”, International Review of Research in Open and Distance Learning, 17(4), DOI: 10.19173/irrodl.v17i4.2409

Chinna, K., and Yuen, C. W. Statistical Analysis Using SPSS (2nd ed.), Kuala Lumpur: University of Malaya, Pearson Publishing, 2015.

Computer Literacy Statistics (2019), Dept. of Census and Statistics, Retrieved from http://www.statistics.gov.lk/CLS/BuletinComputerLiteracy_2009.pdf

Davis, F. D., (1989), "Perceived usefulness, perceived ease of use, and user acceptance of information technology”, MIS Quarterly, 13(3), pp319-340. doi:10.2307/249008.

Edumadze, J.K.E.(2019), “E-Learning At The University Of Cape Coast, Ghana-Are Our Distance Education Students Technologically Ready, The Online Journal of Distance Education and e-Learning, 7(2), pp70-81. Retrieved from www.tojdel.net

Eke, H.N.(2009), “The perspectives of e-learning and libraries in Africa: challenges and opportunities", Library Review, 59(4), pp274-29o.

Fishbein, M., and Ajzen, I.(1975), Belief, attitude, intention and behavior: An introduction theory and research, Reading, MA: Addison-Wesley.

Fernando, M.(2011), "Enhancement of ICT Education via FOSS Solutions in Developing”, Proceedings of International conference for Language Learning, pp 68-76, Florance, Italy: Simonelli.

Hair, J., Black, W., Babin, B., \& Anderson, R.(2010), Multivariate Data Analysis, (7th ed.). Upper Saddle River, New Jersey: Prentice Hall.

Jaiyeoba, O., and Iloanya, J.(2019), "E-learning in tertiary institutions in Botswana: apathy to adoption". The International Journal of Information and Learning Technology, 36 (2), pp157-168. doi:https://doi.org/10.1108/IJILT-05-2018-0058

Khasawneh, M.(2015), "Factors Influence e- learning Utilization in Jordanian Universities-Academic Staff Perspectives", Procedia - Social and Behavioral Sciences, pp170-180. Retrieved from http://www.sciencedirect.com

Kriek, J., \& Stols, G.(2010), “Teachers beliefs and their intention to use interactive simulations in their classrooms", South African Journal of Education, 30, pp439- 456. 
Lai, H.-J. (2017). "Examining civil servants' decisions to use Web 2.o tools for learning, based on the decomposed theory of planned behavior", Interactive Learning Environments, 25(3), pp 295-305, doi:10.1080/10494820.2015.1121879

Lee, B.-C. (2009). "Learners' acceptance of e-learning in South Korea: Theories and results", Computers and Education, 53(4), pp 1320-1329. doi:10.1016/j.compedu.2009.06.014

Mou, J., Shin, D., Cohen, J.(2016), "Understanding trust and perceived usefulness in the consumer acceptance of an e-service: a longitudinal investigation”, Behaviour $\mathcal{E}$ Information Technology, 36(2), pp125-139.

Ndubisi, N. O.(2004), "Factors influencing e- learning adoption intention: examining the determinant structure of the decomposed theory of planned behavior constructs", proceedings of HERDSA conference, pp. 251262. available at : https://www.researchgate.net/publication/265240354

Nunnally, J.(1978), Psychometric theory (2nd ed.), New York: McGraw-Hill

Ratnapala, S. (2014), “Adopting E- Learning for University Education in Sri Lanka -Peradeniya Perspective”, Proceedings of the Peradeniya University, (p. 105). Retrieved from http://www.pdn.ac.lk/ipurse/2014/proceeding_book/ED/105.pdf

Raza, A., Qazi, S.(2018), Puah, W., and Chin-Hong. Assessing e-learning system in higher education institutes: evidence from structural equation modelling. Interactive Technology and Smart education, 15(1), pp 59-78.

Robert, Ho, (2006), Handbook of Univariate and Multivariate Data Analysis and Interpretation with SPSS, Chapman \& Hall, Florida, 2006.

Roszak, M., Kołodziejczak, B., Półjanowicz, W., Bręborowicz, A., Ren-Kurc, A., and Kowalewski, W.(2015), "Elearning Portal Tools for Medical Education". Studies in Logic, Grammar and Rhetoric, 43(56), pp177-193, doi:10.1515/slgr-2015-0049

Saadé, R., Tan, W., and Kira, D.(2008), “Is Usage Predictable Using Belief-Attitude Intention Paradigm”, Issues in Informing Science and Information Technology, 5, pp. 591-599, Retrievedfrom http://proceedings.informingscience.org/InSITE2008/IISITv5P591-599Saade503.pdf

Santos, L., and Okazaki , S.(2015), "Planned e-learning adoption and occupational socialization in Brazilian higher education", Studies in Higher Education, 1-21, doi:http:// dx.doi.org / 10.108o / 03075079.2015.1007940.

Sekaran, U., and Boogie, R., (2010), Research methods for business, a skill building approach. New York : Willey.

Shih, Y.Y., and Fang, K.(2004), "The use of a decomposed theory of planned behavior to study Internet banking in Taiwan. Internet Research, 14(3), pp213-223, doi:10.1108/10662240410542643

Suraweera, N., Liew, C., and Cranefield, J.(2014), "Introduction of E-Learning in Information Management (IM) Education in Sri Lanka: The Influence of Social and Cultural Factors". Annual International Conference on Education \& e-Learning, doi:10.5176/2251-1814_EeL14.29

Tarhini, A., Hone, K., Liu, X., Tarhini, T.(2017), "Examining the moderating effect of individual-level cultural values on users' acceptance of e-learning in developing countries: a structural equation modelling of an extended technology acceptance model", Interactive Learning Environments, 25(3), pp306-328. DOI: 10.1080/10494820.2015.1122635

Taylor, S. and Todd, P.A.(1995a), "Understanding Information Technology usage: a test of competing models". Information systems Research, 6(2), pp144-176.

Taylor, S. and Todd, P.A.(1995b) "Decomposition and crossover effects in the theory of planned behavior: A study of consumer adoption intentions”, International Journal of Research in Marketing, 12, pp137-155, 1995b

Taylor, S. \& Todd, P. A.(2001).Understanding Information Technology Usage : a test of competing models, Information Systems Research. 6(2),144-176. 
17 Moderating Effects of Academic Position and Computer Literacy Skills on E-learning Portal

Usage: SEM Application on Theory of Planned Behaviour

Thowfeek, M. H., and Jaafar, A.(2012), “Instructors' View about Implementation of Elearning System: An Analysis based on Hofstede's Cultural Dimensions". Procedia - Social and Behavioral Sciences 65, 961-967.

Wenchieh, W., and Hwang, L. Y.(2010), "The effectiveness of e-learning for blended Courses in colleges: a multi-level empirical study”, International Journal of Electronic Business Management, 8(4), pp312-322.

Yatigammana, M., Johar, M. G., and Gunawardhana, C., (2014), "Impact of Innovations Attributes on e-learning Acceptance among Sri Lankan Postgraduate Students”, Kelaniya Journal of Management, 2(1_, pp1-17. doi:http://doi.org/10.4038/kjm.v2i1.6541 